\title{
A tropical skin eruption
}

\author{
Christina Greenaway MD
}

\begin{abstract}
21-year-old woman presented to the infectious dislease clinic complaining of a three-day history of a rash on her hands, arms, upper back and thighs. The rash began on the day that she returned to Canada after a oneweek vacation at a resort in Cuba. The rash appeared simultaneously on all sites, was nonpruritic and moderately tender. There was no history of fever, chills, myalgias, arthralgias or other systemic symptoms. The patient did not have any urinary, gastrointestinal, cardiac or pulmonary symptoms. She denied illicit drug use and was not taking any medication.
\end{abstract}

On examination, she was nontoxic and the only abnormalities were restricted to the skin examination. There was linear, red streaking on the right forearm (Figure 1, left), a tender red circular area $(3 \times 4 \mathrm{~cm})$ on the right thigh, nonuniform red macules on the posterior aspect of the neck, and blisters between the fingers of the right hand (Figure 1, right).

What is your diagnosis?

continued on page 142
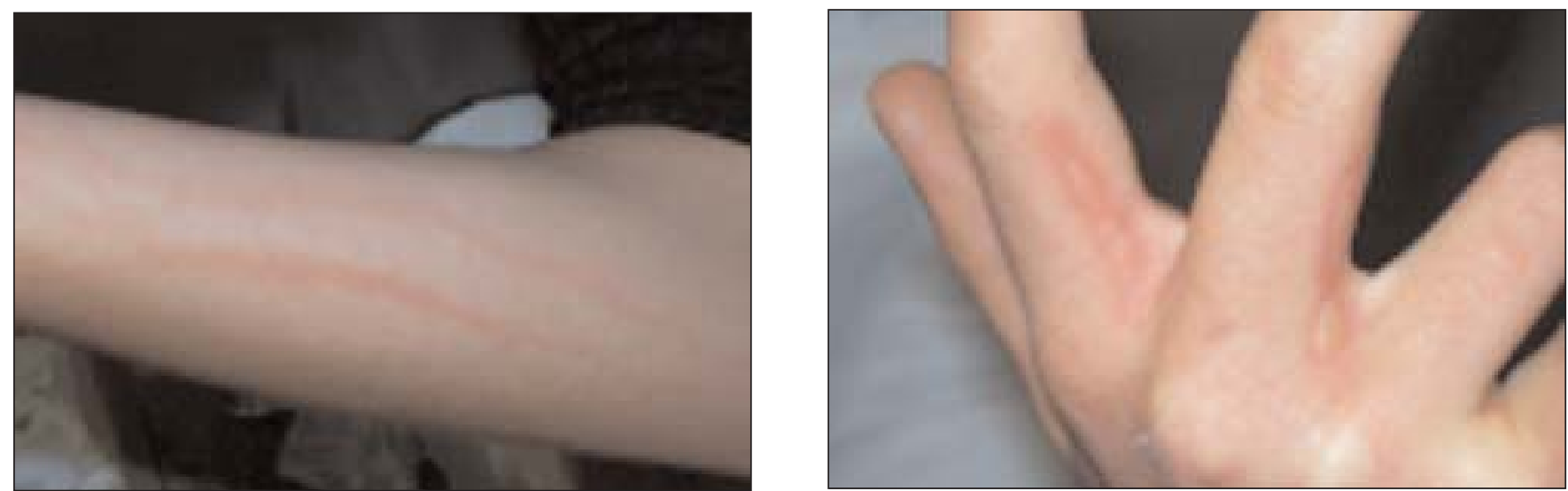

Figure 1) Left Linear red streaking on the patient's right forearm. Right Blisters between the fingers of the patient's right hand

Division of Infectious Diseases, SMBD-Jewish General Hospital, McGill University, Montreal, Quebec

Correspondence and reprints: Dr Christina Greenaway, SMBD-Jewish General Hospital, Department of Microbiology, Division of Infectious Diseases, Room G-143, 3755 Cote-Ste-Catherine Road, Montreal, Quebec H3T 1W9. Telephone 514-340-8222 ext 2933, fax 514-340-7578, e-mail ca.greenaway@mcgill.ca 
TABLE 1

Common plants associated with phytophotodermatitis

\begin{tabular}{ll}
\hline Plant family & Common name of plant \\
\hline Rutaceae & Lemon, lime, persian lime, bergammot \\
Umbelliferae & Celery*, carrots, parsley, parsnip, fennel, dill \\
Moraceae & Fig \\
Ranunculaceae & Buttercup \\
Cruciferae & Mustard \\
\hline
\end{tabular}

*May cause generalized photosensitivity after ingestion

Phytophotodermatitis closely resembles contact dermatitis or chemical burns. Its diagnosis is based on the presence of a rash (often with unusual and nonuniform shapes that are restricted to sun-exposed areas), recent exposure to photosensitizing plants and intense sunlight, and post-inflammatory hyperpigmentation $(1,4)$. A detailed history and the pattern of the rash help differentiate phytophotodermatitis from other conditions. Information regarding recent travel and exposure to citrus fruits (particularly in alcoholic beverages or during food preparation) should be sought.

The rash occurs in areas where plant juice has come into contact with the skin; therefore, if citrus fruit has been squeezed into drinks or into food, the lesions may appear as linear streaks where droplets of plant juice have dripped down the affected body part. The hands and mouth are often involved secondary to eating and handling the offending plant. The rash typically appears 36 to $72 \mathrm{~h}$ after exposure to plant juice and sun. Lesions are heterogeneous in size and shape, ranging from red macules to areas that resemble second-degree burns, with tender erythematous areas, blisters and bullae. In severe cases, the rash is accompanied by systemic toxicity that includes fever, nausea and vomiting. The rash, erythema and vesiculation last for one to two weeks and are followed by a characteristic grey-brown healing hyperpigmentation (postinflammatory) that can persist for weeks or months $(1,4)$.

Treatment is directed toward symptomatic relief. Interventions are aimed at decreasing the inflammatory response, and include cool wet dressings, soothing lotions, topical corticosteroids and systemic antipruritic agents (1). Systemic corticosteroids can be used in severe cases or when lesions are too extensive for topical therapy to be practical or effective (4). Sunscreen should be used to avoid any further hyperpigmentation when the patient is outside. Use of a bleaching agent such as $4 \%$ hydroquinone can be used if skin discoloration is bothersome (5).

\section{REFERENCES}

1. Gould JW, Mercurio MG, Elmets CA. Cutaneous photosensitivity diseases induced by exogenous agents. J Am Acad Dermatol 1995;33:551-73.

2. Lovel CR. Phytophototoxic reactions. In: Lovell CR, ed. Plants and the Skin. Boston: Blackwell Scientific, 1993:64-95.

3. Lovell CR. Phytodermatitis. Clin Dermatol 1997;15:607-13.

4. Juckett G. Plant dermatitis. Possible culprits go far beyond poison ivy. Postgrad Med 1996;100:159-71.

5. Weber IC, Davis CP, Greeson DM. Phytophotodermatitis: the other "lime" disease. J Emerg Med 1999;17:235-7. 


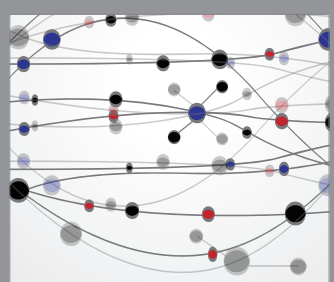

The Scientific World Journal
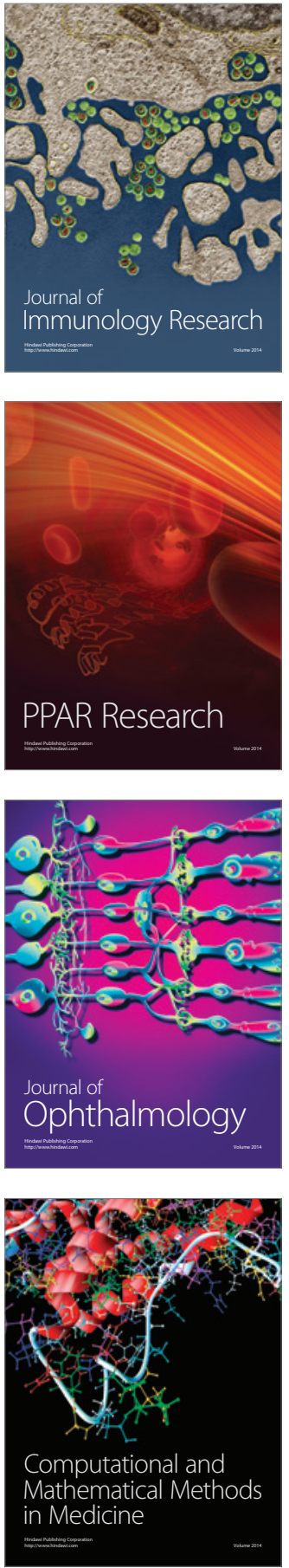

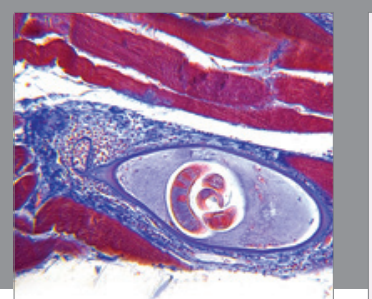

Gastroenterology Research and Practice

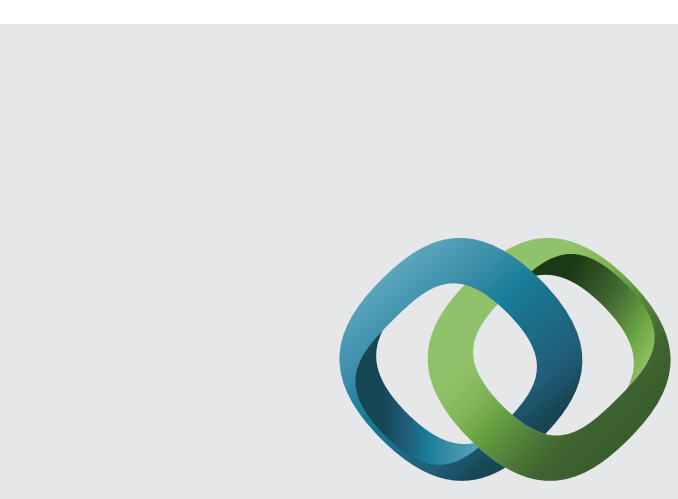

\section{Hindawi}

Submit your manuscripts at

http://www.hindawi.com
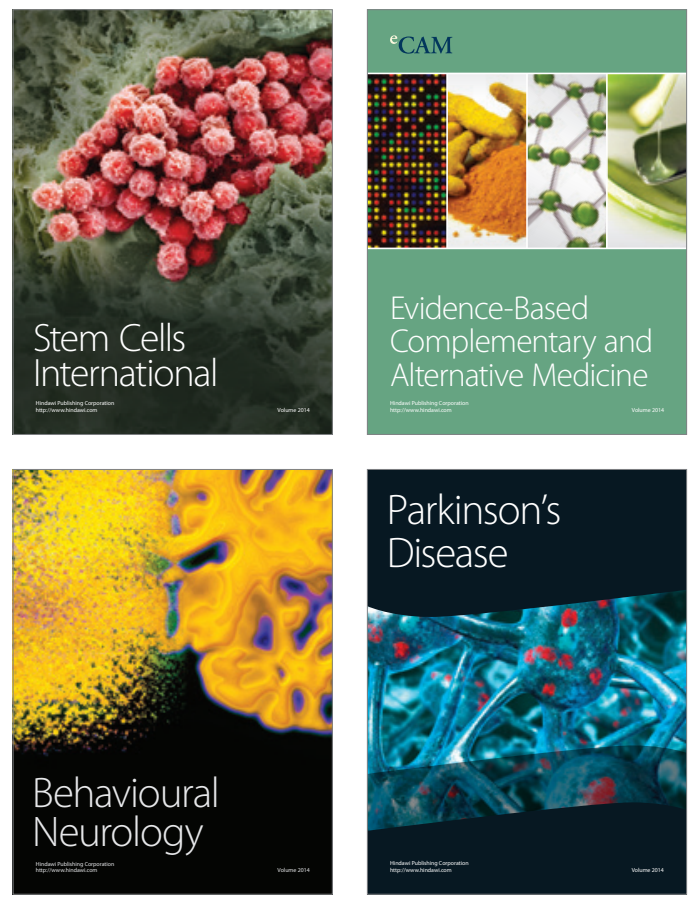
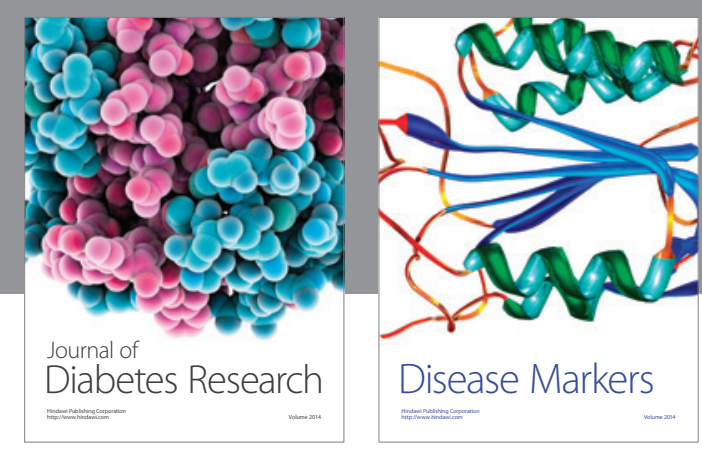

Disease Markers
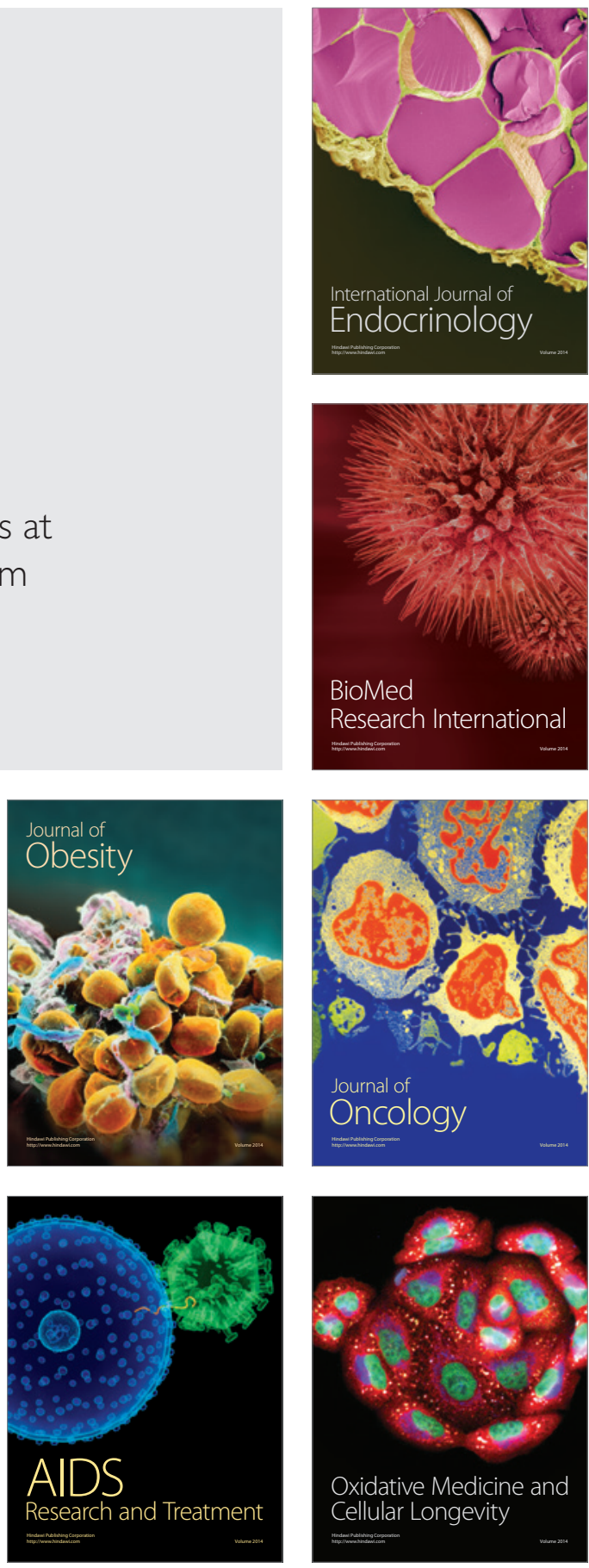